\title{
LA EDUCACIÓN FAMILIAR COMO MODELO PARA CONTRARRESTAR LA VIOLENCIA
}

Salvador Peiro i Gregori

\section{RESUMEN}

Los sucesos circumescolares inciden en la generación de un clima que contraría los fines de la educación. Este trabajo muestra cómo la violencia de la calle contamina el desarrollo curricular, la organización, la orientación... El autor efectúa una reflexión a partir de informes de los medios de comunicación y otras fuentes sociológicas. Luego profundiza en las causas, induciéndolas mediante un cuestionario elaborado y aplicado. A consecuencia de tales factores, se infieren propuestas para la práctica. El modelo se centra en la optimización de las familias en situación de riesgo de violencias: reeducación de padres, tutoría... Para establecer las líneas de concreción, ofrece referencias con relación a estrategias y técnicas de un plan de actuación interdisciplinario.

\section{INTRODUCCIÓN}

En el decenio 1985-1995', los crímenes violentos perpetrados por menores aumentaron al menos un $50 \%$ en diez países

\footnotetext{
${ }^{1}$ Estudio efectuado por el doctor Christian Pfeiffer, del Instituto de Estudios Criminológicos de la Baja Sajonia. Le Monde, 28-1-1998. Las aportaciones tomadas de la prensa se sitúan en el pleno sentido de ofrecer la incidencia social de la problemática. En cuanto a la cientificidad de tales aportaciones, el investigador que refiere las citas ofrece tal grado de credibilidad cuanto la misma fuente (sea un Instituto Universitario, o una revista de solvencia reconocida). Por ejemplo, si comparamos los datos sobre los principales problemas de la Comunidad Valenciana de 2001, constataremos la casi identidad de los aportados por el diario de Alicante Información (junio de 2001), a partir de los trabajos del Instituto de investigación EMER-GFK y los del CIS (octubre de 2001).
} 
europeos (Alemania, Austria, Holanda, Inglaterra, Suecia, Suiza, etcétera). Así, en Francia, aunque sus cifras delictivas bajaron globalmente, la proporción concerniente a menores creció delictivamente en un 17'8 \% en 1996 a un 19'3 \% en 1997. En Estados Unidos sucedió algo semejante (Newsweek, 9-4-1998): las detenciones de jóvenes por crímenes violentos crecieron, de 1985 a 1995, en un 67\%; en 1997, uno de cada siete asesinatos y uno de cada tres delitos contra la propiedad fueron cometidos por menores.

Con el fin de aproximarnos a la cuestión, compendiaré en primer lugar datos descriptivos recogidos desde modelos sociológicos, proporcionados por mcs e investigaciones universitarias, pasando luego a resaltar la repercusión que tienen en la vida colegial. Para esto diseñé un cuestionario y efectué una encuesta aproximativa sobre los factores causales dentro del aula. Como los centros germinales de tales actitudes son extraescolares, aspecto que tiene bastante ligazón con la función tutorial, señalamos unos lineamientos para la actuación circumescolar, sobre todo para orientar a las familias. Esto puede ser recogido por los educadores de calle, o sociales, o de educación de adultos para encarnar sus actuaciones.

Las cuestiones que inician el trabajo son: si tales son los datos sobre comportamientos violentos, ¿cómo estamos en nuestras ciudades?, ¿cómo son las relaciones entre los sujetos de la vida real y académica?, ¿qué consecuencias conllevan para desarrollar los procesos educativos?, ¿por qué?, etcétera. Empecemos por analizar la vida cotidiana.

\section{LOS HECHOS DE LA CALLE SE INTRODUCEN EN LAS AULAS}

Esto se analiza desde la perspectiva del binomio violenciadelincuencia. Ignacio Cosidó, jefe del gabinete del Director General de la Guardia Civil, distingue ${ }^{2}$ tres esferas delincuenciales

\footnotetext{
${ }^{2}$ "Foro sobre la violencia juvenil", Pamplona, 23-XI; cfr. Información, 26-XI-2000.
} 
en el Estado Español: i) juvenil; ii) emergente de ciudad; y iii) kale borroka. Entre los tipos, tenemos que las acciones principales son de negligencia ( $71 \%$ de los casos), siendo la mujer la principal agente; por otro lado, los varones protagonizan mayor número de abusos sexuales y físicos. A su vez, Cosidó categoriza como violencias emergentes en los siguientes ámbitos: a) escolar; b) urbana; c) racista; y d) deportiva. Añade, además, que si bien los índices no son preocupantes, la situación sí puede evolucionar negativamente. Esto lo justifica por la tendencia al alza, en comparación de delitos cometidos en 1999 respecto al resto de Europa.

En Alicante ${ }^{3}$, los casos de maltrato a menores se duplicaron en un año. Al comparar datos de 1991/92 con los de $1997 / 98$, se constata un incremento del varón como perpetrador (40\% de casos), mas la mujer continúa siendo la principal maltratante con un 60\% de las acciones. En la Comunidad Valenciana, las ciudades con población situada en número entre 5.000 y 50.000 almas, producen más del 50\% de violencias intrafamiliares. Y, ante esto, aprecio positivamente que la Asociación de Vecinos (del barrio) Juan XXIII ${ }^{4}$ haya denunciado la creciente violencia que sacude el barrio: tropiezan todos los días con situaciones desagradables, de trapicheo, peleas e incluso tiros, oleada de robos en domicilios... Aducen que, cada día, todo esto va a más.

En tal contexto, durante el último semestre de 1997, los expertos educacionales de la UE celebraron diversas reuniones para tratar el problema de la violencia escolar. El equipo de investigación que dirige Charlot $^{5}$ distingue diversos tipos de

\footnotetext{
${ }^{3}$ Informe elaborado por el Centro Reina Sofía para el Estudio de la Violencia. Información, 14-XII-2000. Se reafirman los datos y las tendencias que ofrece Sanmartín, J. (2000). La violencia y sus claves. Barcelona, Ariel, pp.78 y ss. ${ }^{4}$ Información 9-XII-2000. En 2002 se constatan tiroteos entre bandas en plena calle y de manera reiterada. Confróntese la prensa de la última semana de abril. ${ }^{5}$ Bernart Charlot es Profesor de la Universidad París VIII, en la Sección de Ciencias de la Educación. Ha dirigido las investigaciones de un comité a las órdenes de los Ministerios de Educación e Interior franceses. Le Monde de l'Éducation, febrero de 1997.
} 
violencias, pero señala que no deben preocuparnos tanto los más llamativos —que subrayadamente presentan los medios de comunicación social一, y sí en cambio los más cotidianos, menos acentuados y frecuentes por ser éstos menos controlables (faltas de respeto entre compañeros, 48\%; trabajos estropeados, 28\%; extorsiones, 16\%; golpes, 16\%; racismo, 10\%; y agresiones sexuales, 3\%). La xenofobia contra emigrantes es un acto más de la violencia gratuita. Los caballos de batalla en los centros del sistema educativo ${ }^{6}$ son la indisciplina, junto con la abulia; los comportamientos graves con armas son aislados.

Su traducción educacional es la falta de asistencia al centro docente. También su materialización son las situaciones de violencia en las escuelas ${ }^{7}$. El trabajo expresa claramente que los muchachos educados negligentemente, en edades comprendidas de 9 a 15 años, suelen efectuar agresiones entre sí, portando cuchillos y revólveres. En principio, Zuckerman ${ }^{8}$ interconecta una serie de hábitos (no planteo sólo lo externo al sujeto), alcoholemia, adicción, promiscuidad sexual y una "delincuencialidad" prematura, etcétera, como una constelación de comportamientos; el absentismo es uno de los hábitos negativos.

Se registran graves incidentes en diversos centros escolares, donde son agredidos tanto alumnos como profesores. Pero lo "novedoso" es que se trata de jóvenes no pertenecientes a los propios centros escolares, pero que están implicados e incitados por los estudiantes del centro violentado?. No se trata de casos esporádicos, sino que es una continua situación de hecho. Es otro tipo de punta del iceberg de la violencia

${ }^{6}$ Ortigosa, S. (1996) Informe de España 1996. Madrid, Fundación Encuentro. ${ }^{7}$ Brown, W. y DeLapp, L, (1995) Stopping the violence: Creating safe passages for Youth. California State Legislature. Sacramento, cap. $2^{\circ}$.

${ }^{8}$ Zuckerman, B. et al. (1989) Niños en riesgo: problemas sociales y médicos. México, Interamericana, pp.53 y ss.

${ }^{9}$ CSI-CSIF. Sector de Enseñanza de Sevilla (2001). Debate profesional. Año XIII, $\mathrm{n}^{\circ}$ 114, Tercera época. 
educacional, que repercute en los procesos intraacadémicos, derivándose una contaminación exponencialmente negativa para los climas de aprendizaje.

\section{FACTORES IMPLICADOS CON LA VIOLENCIA ES- COLAR Y CLIMA EDUCACIONAL DEL AULA DOCENTE}

Es obvio distinguir y relacionar ${ }^{10}$ los conceptos agresividad (connatural), disciplina, castigo, interacción, violencia, dignidad personal y educabilidad, entre otros. Entre los factores relacionados con la casuística de la violencia en los centros ${ }^{11}$, tenemos los siguientes:

a) Deficiencias en los valores sociales en donde el sujeto se socializa primariamente.

b) Falta de legitimación de los valores escolares, que están en disintonía con los vividos en las sociedades en donde se reintegra el educando.

c) Derivados de socializaciones primarias "defectuosas" (adicción a la televisión, malos tratos, sobreprotección, negligencias...); intrapolación en el proceso educacional de problemas personales del estudiante.

d) Desempeño de la docencia con superespecialización, con excesiva división de funciones, contenidos, formas y tareas. Esto genera una barrera motivacional por descoordinación y alejamiento de la realidad vital.

e) Burocratización y rigidez organizativa de los centros docentes que ocasiona la reducción de la interacción humana a un esquema funcionalista.

\footnotetext{
${ }^{10}$ Lo explico en la revista cultural: Canelobre, del Instituto Joan Gil Albert (Alicante). Núm. diciembre de 2001.

${ }^{11}$ Podría proceder buscando conjuntos de factores, ya se mencionó en $L a$ educación del niño en riesgo (1993), tal como aducen AA.VV. (2001) en Conflicto, violencia y educación (Cajamurcia, pp.97 y ss). Insertamos investigaciones de Branbeck, C.S. (1977) Sociología de la educación, Buenos Aires, Paidós, cap. 3o. También se incluyen aportaciones de Brameld, T. (1968) Illusions and desillutions in Ametrican Education, Kappan, L, no 4, pp. 20042007. Además se contemplan las tesis de Hurrelmann, cfr: Hanke, Huber y Mandl (1979: El niño agresivo y desatento. Buenos Aires, Kapelusz), pues resultan más sistemáticas en cuanto a la definición curricular.
} 
f) Estructuración del sistema escolar (desde infantil a universidad) en función de esquemas rígidamente prescritos, marginando la necesaria cohesión social.

g) Centrarse en el único rol de rendimiento, pero unido a la inalcanzabilidad de los objetivos del ciclo o nivel, paulatinamente disminuye la motivación.

En abril de 2000, abordamos el estudio empírico ${ }^{12}$ de los tipos y factores de la violencia en el aula escolar a través del desarrollo de un seminario con docentes internivel interesados en ello. Sobre la relación entre los tipos de violencias y los factores causales, los participantes y docentes de diversos centros consultados, tienden a converger al señalar el gran peso que tienen los hábitos adquiridos durante los procesos educativos de socialización primaria: familias, amistades, pandillas, etcétera. Baste comparar tales factores y su incidencia, según los datos que proporciona el siguiente gráfico.

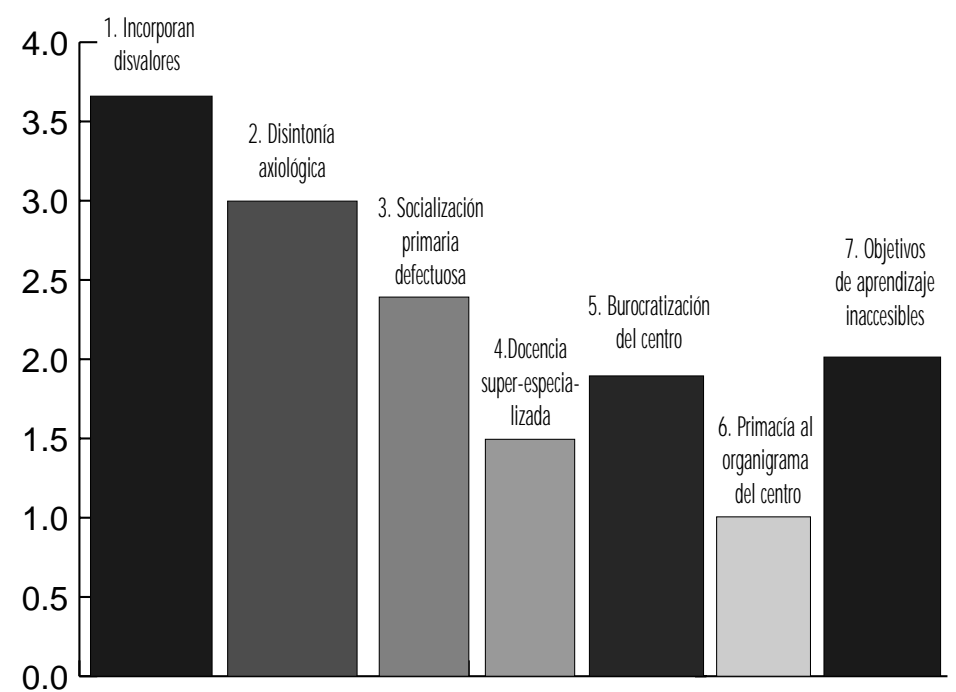

${ }^{12}$ A partir de 148 cuestionarios contestados, hemos calculado usando estadísticos descriptivos, ya que no se ha podido efectuar un estudio relativo a varios grupos, condición para la inferencia. En el gráfico ofrecemos las medias. 
Considerando los datos que proporciona la inducción, los factores estructurales no son tan apreciados como los restantes, no obstante, no dejan de tener cierto peso en la influencia sobre la educatividad del centro. Los encuestados opinan que son más cualificantes (delatores del clima del aula) los siguientes: posibilidad de lograr los objetivos de aprendizaje, por una parte, y el sistema de relaciones (burocratización o no) en la institución. Pero los que ofrecen mayores muestras discriminatorias son las tres columnas primeras: socialización primaria defectuosa (¿quiénes malcrían a los estudiantes?); disintonías en las propuestas de valores en los centros, familias, grupos de amigos; y la incorporación con los alumnos de disvalores (o antivalores) desde fuera de la institución escolar. Y todo esto es relevante, puesto que trasciende el rendimiento académico y ocasiona derivaciones en la salud mental de los afectados.

Tales factores promueven situaciones de crianza, socialización primaria, con sus procesos informales de educación, materializados en formas de pobreza, desorganización, violencia familiar... Lo que distingue este hábito agresivo de la enfermedad, en tanto que carencia de salud, es la causalidad física, cuya responsabilidad compete al médico (p.e.: asma o diabetes). Por consiguiente, ni se trata de herencia, ni de enfermedad; la violencia es cuestión de actitudes axiológicas y procesos educacionales.

\section{PARA RESALTAR LA INCIDENCIA DEL CONTEXTO EDUCACIONAL INFORMAL, CONSTATEMOS UNA CA- SUÍSTICA EXTREMA: LA VIOLENCIA DELINCUENCIAL}

Uno de los casos hacia los que deriva la violencia es el fenómeno de la delincuencia ${ }^{13}$. Sin referirnos a crímenes, sí

${ }^{13}$ En una primera publicación del autor (Educación del niño en riesgo, edt. Adhara-Unesco, Las Gabias-Granada, 1993, pp. 169-187), aparte de definir el contexto de riesgo y los casos paradigmáticos de situaciones de riesgo, perpetradores y casuísticas, planteamos los lineamientos para la sistematización pedagógica respecto a la prevención y reeducación de los afectados. 
podemos apreciar los datos sobre los sujetos que participan de la doble dimensión que analizamos. ¿Hasta qué punto podemos hablar de unos factores extrasubjetivos dinamizadores de la violencia, incapaces de transformar la agresividad en energía humanizante?, ¿qué valores se generan de tales condiciones?, ¿en dónde se halla la dificultad matriz?

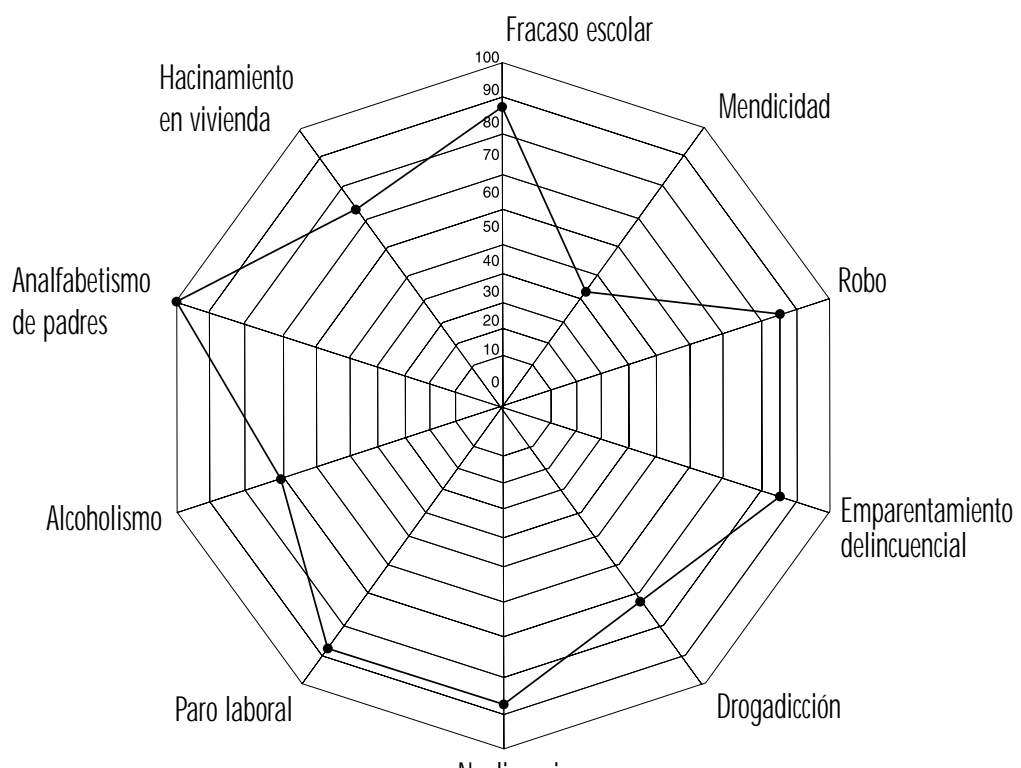

Negligencia

La situación de riesgo para el menor, objeto de violencias, ofrece un contexto sociocultural plasmado en un ethos condicionantemente negativo. Los datos ${ }^{14}$ del gráfico los ofrece el Consejo Superior de Protección del Menor ${ }^{15}$. Esto se relaciona con que la violencia educacional no está configurada por factores simples y está muy correlacionado con la falta de asistencia a la escuela. De estas premisas concluimos que los contextos de las instituciones educativas son más relevantes de lo que se pensaba. El grado de cultura (analfabetismo, como situación más

${ }^{14}$ En La escuela ante los abusos y malos tratos (Granada, GEU, 1997) se hace referencia al conjunto de fuentes que me sirvieron para elaborar esta propuesta.

${ }^{15}$ Cfr. Revista Infancia y sociedad, $\mathrm{n}^{-}$de 1989. 
baja), el tipo de normatividad (negligencias) y el emparentamiento delincuencial, junto al fracaso escolar son los que más peso tienen en las situaciones extremas de violencia.

Sin embargo, si bien constatamos deficiencias en cuanto a enculturación (lengua, religión, estética...) y socialización (normas, costumbres, actitudes...), no nos concreta mucho el aspecto relativo a los valores. Y éstas son cuestiones claves para cualificar la educación.

Podemos deducir que este problema se engarza principalmente con la temática del SITE ${ }^{16}$, a través de la consideración de la crianza familiar. Lo cual da pie a definir etnológicamente la subcultura de riesgo. Esto porque, en palabras de la coponente, el comportamiento bumano es un reflejo de lo que le acontece (al sujeto en situación de riesgo) y no una consecuencia de sus impulsos innatos, pues en contextos no agresivos, el niño aprende, desde muy pequeño, que es más eficaz expresar lo que quiere mediante lenguaje que recurriendo a la agresión, ya que la violencia genera violencia, como hacemos notar ${ }^{17}$ sobre el círculo vicioso de la deficiencia infantil.

Además, todas las formas de agresión suelen estar interconectadas. Los análisis factoriales así lo indican ${ }^{18}$. Por consiguiente, ni se hereda el impulso, ni el temperamento está determinado hacia la catarsis. En cuanto más agresión exista en el ethos educacional, mayor será el riesgo de conjugar los anteriores factores descritos arriba. Más concretamente, si se presentan los tipos de agresión verbal, simbólica, física, emotiva, etcétera, no ocurren de modo paralelo ni aislados. Hay una cadena, casi imparable. Por esto, más que sustituirse entre sí, se relacionan, ocasionando una la siguiente, cada vez con más daño.

\footnotetext{
${ }^{16}$ Seminario Interuniversitario de Teoría de la Educación (SITE). Se trata de la aportación relativa a una investigación de Pérez Alonso-Geta, $\mathrm{P}^{\underline{a}} \mathrm{M}^{\underline{a}}$ y Canovas, P. , que se puede leer en: (1996) Informe sobre la realidad de la infancia en el seguimiento de cero a seis años. Madrid, INCIE-Fundación Santa María.

${ }^{17}$ Educación del niño en riesgo. Adhara-UNESCO, Las Gabias-Granada. 1993; p.226.

${ }^{18}$ Russell, E.W. (1972) Factors of human agression: a cross-cultural factor analysis of characteristic related to warfare and crime. Behavior Science Notes, vol. $.97, n^{\circ}-4$.
} 
Por consiguiente, los comportamientos violentos están más allá de la impronta psicobiológica; han de plantearse desde el condicionante socio-cultural de la educación. Esto manifiesta que la violencia se aprende culturalmente. Y hablar de cultura conlleva ${ }^{19}$ referirse a un estilo de vida total que puede definirse $^{20}$ como sistema de conocimientos que opera a modo de modelo de la realidad. Esto da orden, coherencia, integración y dirección a las acciones sociales de los ciudadanos que la generaron y la transmiten, así como a quienes la aprenden. Se adquiere socialmente a través de modos pautados y recurrentes de pensar, sentir y actuar. Por consiguiente se efectúa un aprendizaje a través de grupos concretos que manifiestan un todo complejo de conocimientos, creencias, arte, moral, derecho, costumbres y una serie de capacidades y hábitos.

Tal ethos no se hereda genéticamente, se transmite y se aprende ${ }^{21}$, aunque provocado y sostenido por un sustrato fáctico, entre cuyos factores contamos con el ambiente. Por esto podemos plantear la situación como circular, el círculo vicioso ${ }^{22}$ para la situación y como hipótesis de trabajo. Altamirano ${ }^{23}$ asocia un estrato social específico con un estilo de vida. En consecuencia, subrayamos el papel central que juega la familia para prevenir y recuperar los casos de violencias escolares.

En consecuencia, uno de los aspectos a considerar es la consecuente urgencia de actuar con las familias, fortaleciéndolas, si se desea ser efectivo. Por tanto, para prevenir y actuar con relación a los malos tratos, habría que:

a) Ayudar a los perpetradores, promoviendo la salida del túnel del círculo vicioso.

${ }^{19}$ Harris,M. et al., (1991) Introducción a la antropología general. Madrid, Alianza.

${ }^{20}$ Aguirre, A. (1982) Conceptos clave de antropología. Madrid, Daimon; vOZ "cultura".

${ }^{21}$ Bouché, H. (1996) Etnocultura y pobreza. Ponencia al III Congreso Internacional de Filosofía de la Educación: Antropología y educación (policopiado, p.5). Madrid, UNED.

${ }^{22}$ Myrdal, G. (1944) Amerycan Dilema. Nueva York, Harper and Brothers; p.1065.

23 Cfr. Cultura andina y pobreza urbana. Lima, Pontificia Universidad Católica. 1988, p.22. 
b) Generar situaciones socioculturales que promuevan la cohesión de los núcleos de socialización primaria y educación informal, mediante la siembra de valores humanizantes.

\section{PROPUESTAS PARA EMPRENDER ACCIONES PEDAGÓGICAS}

De lo anterior podemos extraer varias conclusiones. La violencia se adquiere con la dinámica cultural, siendo un proceder de aprendizaje como cualquier cultura. Se trata de una realidad subcultural, pero no territorial o zonal; es vivencial. Está actualizada por individuos y mediante grupos específicos, principalmente familias. Además, ciertos factores contribuyen a acelerar tales abusos. Por consiguiente, los valores y los hábitos negativos (ethos específicos) son la clave para reconocer tales lineamientos subculturales. Y, como la agresividad negativa configura una situación enfermiza ${ }^{24}$, los epifenómenos violentos son factores degenerativos de una salud mental humana.

La educación tiende ${ }^{25}$ a actualizar las potencialidades humanas (inteligencia y voluntad), que al principio de la vida se dan como disposiciones. Esto posibilita la autorrealización del sujeto, que ha de ser en sociedad, mediante los educadores principales (padres, maestros, sacerdotes —en su caso—, líderes, ...) y secundarios (compañeros de juego, de clase, novios; personalidades creadoras de cultura, de instituciones, etcétera). En tales situaciones entran las vivencias positivas y las dolorosas. Éstas pueden causar las transformaciones como las referidas en los casos de sujetos maltratados. Y aquí hay que distinguir entre riesgo y las contrariedades de dolor en la vida cotidiana, como es el castigo.

La comprensión de las relaciones familiares es requisito para entender el fenómeno de riesgo de malos tratos y su red factorial; generativos de la violencia escolar. Así es como empieza a desarrollarse y afecta las percepciones y competencias del niño víctima. Por esto, es conveniente investigar el maltrato

${ }^{24}$ Cloutier, F. (1967) La santée mentale. Paris, PUF; pp.21-23 y 81-88.

${ }^{25}$ Henz, H. (1968) Tratado de Pedagogía sistemática. Barcelona, Herder; pp.44 y ss. 
a partir de contemplar la incidencia de los factores en su vida cotidiana — también aquí, la escuela-, entre cuyos educadores secundarios incluimos la relación entre familias y sus orígenes biográficos ${ }^{26}$. El carácter sistémico de la configuración de la personalidad en el seno de la familia nos lleva a explicar el modo de valorar sus prácticas violentas y los valores sustentadores de la misma, así como qué virtudes carenciales se constatan en los adultos que la componen.

Si los factores definitorios de situaciones de riesgo de violencia (abusos, malos tratos, negligencias) son un conjunto de disvalores concretados con hechos observables $\mathrm{como}^{27}$ : pobreza, expectativas de raza y sexo, consumo crónico de bebidas alcohólicas y otras drogas, analfabetismo, escolarización incompleta, absentismo escolar, contacto temprano con violencias familiares, baja autoestima, depresión, antecedentes de lesión o enfermedad en el SNC, mensajes de violencia transmitidos por medios de comunicación social —especialmente televisión-y llevar armas, configuran pautas de grupo. Por consiguiente, no cabe contemplar a los grupos de maltratantes como minorías, pero sí se plantea cierta semejanza con la definición de subcultura, ya que tales caracteres se transmiten de este modo.

Por consiguiente, tales nichos presentan características estructurales de una subcultura, pero no opera en paralelo, sino a contrario. Así que esta situación infracultural conlleva antivalores deshumanizantes a conculcar en los sujetos y sus relaciones, intra y extragrupales. Situación que implica la noción de reeducación ${ }^{28}$ para romper el ciclo de la violencia interindividual, intragrupal e intergrupal adquirida de generación en generación.

\footnotetext{
${ }^{26}$ López-Barajas, E. (1996) Educación y tolerancia. Madrid, UNED.

${ }^{27}$ Cirillo, S. y Di Blasio, P. (1991) Niños maltratados. Barcelona, Paidós; también en Zuckermann y otros: op. cit.

${ }^{28}$ Entiéndase en el sentido positivo, liberalizante; estamos muy alejados de la concepción "reeducacional" como la efectuada contra quienes disentían de régimenes uniformistas y absolutistas, aplicadas por desgracia en campos de concentración, clínicas de salud mental y ciertas instituciones. Educación no es ni dogma, ni adoctrinamiento; así mismo, huye de modelos uniformizantes.
} 


\section{LINEAMIENTOS PARA EFECTUAR UNA PREVENCIÓN Y TRATAMIENTO}

En primer lugar hay que considerar la situación de las intervenciones del tipo "trabajo social". Debemos recordar que los diversos planes de actuación suelen desarrollarse a través de los servicios sociales de los ayuntamientos y diputaciones, centrados en zonas de trabajo social, a tenor de los centros de barrio y sobre familias necesitadas. No obstante, sucede una limitación en cuanto a la prevención y sus consecuencias educativas. Actualmente, la ayuda a las familias maltratadoras aparece cuando ya se ha dado el maltrato contra los hijos. Por lo que ya existen hábitos agresivos interiorizados, consiguientemente, la escuela haría bien poco.

A esto se añade que los servicios sociales a menudo se encuentran con numerosos problemas a la hora de tratar el maltrato infantil ${ }^{29}$. Las deficiencias más frecuentes son las siguientes: a) Las familias que más ayuda necesitan son incapaces de procurársela por sí mismas; b) los afectados suelen llegar a los servicios sociales obligados por alguien, que ha visto el problema desde fuera, cosa que hace que la colaboración por su parte sea escasa; c) los padres perpetradores no quieren admitir que tienen un problema por miedo a perder la custodia de sus hijos.

En consecuencia, no se están consiguiendo grandes resultados. Las acciones más extendidas van dirigidas a proteger a los niños, no a tratar o reeducar a esos padres que maltratan a sus hijos. Esto se debe a que persisten una serie de problemas que bloquean los procesos de las acciones sociales. Éstos se hallan incluidos entre los factores que describen cada uno de los modelos explicativos de la violencia; los traemos aquí para hacerlos presentes en aras a interpretar las notas que siguen para caracterizar a los sujetos perpetradores:

${ }^{29}$ Sanmartín, J. (1999) Violencia contra niños. Barcelona, Ariel. 
a) Por lo general, los padres que maltratan a sus hijos tienen alguno de estos problemas: alteraciones emocionales, problemas de aprendizaje y deficiencias en la personalidad que limitan la capacidad de adaptación y resolución de problemas.

b) Excitación emocional y reactividad ante la provocación del niño.

c) Esto acarrea una práctica disciplinaria con escaso control de la ira y la hostilidad. Se trata de usar métodos inadecuados e inapropiados de enseñanza, disciplina y estimulación.

d) Alteración de la percepción y expectativas que se tienen de los niños (ideas rígidas acerca de la educación).

e) Estilo de vida y hábitos perniciosos que influyen negativamente en la relación entre padre e hijos, y en la capacidad de solucionar problemas.

De estas premisas sacamos en consecuencia que una de las metas debería dirigirse a fortalecer el carácter de los cónyuges. Sin embargo, también hay que formarles para desempeñar su principal función dentro del matrimonio: maternidad y paternidad.

Para que la actuación en este campo fuera exitosa, los programas deberían tender más a reeducar a los padres, centrándose mejor en los procesos personalizantes, sobre todo en cada miembro del hogar en crisis. Por consiguiente, desde la perspectiva de la estructura, problemas y disvalores de tales familias nucleares, señalamos los siguientes objetivos mínimos:

a) Fomentar relaciones positivas entre padres e hijos.

b) Capacitar a estas familias para resolver los conflictos de una forma no violenta...

\section{UN MODELO PEDAGógICO PROPUESTO PARA VALORAR}

El tratamiento (institucionalización) más utilizado con los niños maltratados ha sido el de alejarlos de sus familias, sea mediante el acogimiento temporal, "residencialización". Esto es bueno porque aleja al niño del riesgo de sufrir daños por sus familiares perpetradores; a la vez que proporciona tiempo 
a los padres para someterse a tratamiento y rehabilitarse antes de que el niño regrese.

Aunque estudios han demostrado que este sistema ofrece errores, sobre todo de tipo afectivo, autoestima e inseguridad, entre otros. Otra situación es la ubicación en familias adoptivas indefinidamente, considerándoles como hijos, pero ésta no es la mejor situación. Uno de los errores principales es que los programas de tratamiento del maltrato se centran sobre todo en separar a los niños de los padres; incluso, a costa de un maltrato emocional, aunque bastante afectados van de familia en familia, con rechazo tras rechazo. Esto repercute en la situación escolar, aunque son los menos. Así, observan que los niños maltratados han sufrido grandes carencias en su proceso de desarrollo y, por tanto, necesitan atención especial para superar las deficiencias ante los problemas de entre los enumerados y otros que pudieran sufrir.

Se encuentran los siguientes problemas:

1. Deficiencias de socialidad, manifestada en el establecimiento de relaciones. Esto se traduce en carencias de empatía, confianza en otras personas y expresiones de afecto.

2. Pobreza en el desarrollo cognitivo, lenguaje y moralidad, materializado en una pobre valoración social, una deficiente capacidad comunicativa y un bajo rendimiento escolar.

3. Problemas de autocontrol de la agresividad natural, que degeneran en violencias.

4. Cuestiones relativas a la salud, la seguridad y la protección. Por tanto, la intervención debe ser bifronte, entre sujetosriesgo: víctimas y familiares. Esto presupone que ha de alcanzarse un tratamiento que optimice la educatividad de los padres, a la vez que proteja a las víctimas, sin desintegrar el hogar. Por ejemplo, la Bernard van Leer Foundation ${ }^{30}$ tiene publicaciones

${ }^{30}$ Una amplia referencia sobre programas, publicaciones, recursos, experiencias, etcétera, la ofrece la Barnard van Leer Foundation en: Enhancing the Skills of early chilhood trainers. Oxford \& IBH Publishing. La experiencia más reciente está en Thomas, A. (1999) The Cynon Valley Project, La Haya, Bernard van Leer Foundation. 
que reflejan experiencias desarrolladas según esta premisa. Lo que varía en este sistema es que se trata de voluntarios paraprofesionales de educación; no implica la función exclusiva de enfermeras, ni asistentes sociales. Aquí prima la función pedagógica, pero sin estar a cargo de especialistas.

De todos modos habría que observar, y bajo la perspectiva del seguimiento y valoración longitudinal, la situación a corto plazo de los afectados. ¿No podría compararse con otros que hayan seguido procesos reeducativos relativos al mundo de los valores humanos? A tal efecto sería aconsejable implicarse en el desarrollo de programas que les capaciten en la autonomía moral ${ }^{31}$.

Hay experiencias plasmadas en informes y libros ${ }^{32}$ que preparan para superar los conflictos y crisis matrimoniales. Tales son tan cargantes como para convertirse en situaciones propensas a procesos de riesgos. Éstas se rigen por los siguientes principios: los factores de las crisis matrimoniales y las claves de la felicidad; factores de cohesión en el hogar; matrimonio y sexualidad, y dinámica de la comunicación ${ }^{33}$ matrimonial y familiar.

Sistemáticamente nos situamos en un problema fundamental: los padres y su función de educar completamente a los hijos. Ésta es una cuestión estrictamente pedagógica o psicopedagógica. Sobre esto hay bastantes experiencias, incluso en educación de adultos ${ }^{34}$. El motivo se debe a las características de las personas perpetradoras que carecen de habilidades para educar a sus hijos y su baja capacidad para autocontrolarse. De ahí que el tratamiento dispensado deba orientarse a resolver estas carencias. Los padres maltratantes suelen hacer mucho hincapié en la disciplina, las responsabilidades..., pero no

${ }^{31}$ Cfr. Escámez, J. et al. (1998) Educar en la autonomía moral. Valencia. Consellería de Cultura, Educació i Ciencia.

32 Vázquez, A. (1996) Matrimonio para un tiempo nuevo. Madrid, Palabra.

${ }^{33}$ Isaacs, D. (1986) Dinámica de la comunicación en el matrimonio. Pautas de evaluación. Pamplona, Eunsa.

${ }^{34}$ Peiró, S. (1995) Familia, educación de adultos y hogares en situación de riesgo. Granada, Adhara Ediciones, col. Biblioteca de Estudios Universitarios. 
saben disfrutar de la compañia de sus hijos, por eso el tratamiento también va dirigido a aumentar las interacciones positivas entre los padres y los hijos. Las soluciones presentan las siguientes facetas:

A. La manera de «disciplinar». Se pretende capacitarles para saber...

1. Mantener la calma, pero conservando la firmeza.

2. Expresar la frustración y el enfado sin llegar al maltrato y a la amenaza.

3. Sustituir el castigo físico y la apatía por actitudes más positivas. En este sentido hay que formales para ${ }^{35}$ :

3.1. usar adecuadamente los elogios;

3.2. motivar las conciencias de los hijos;

3.3. fortalecer la voluntad;

3.4. prever el futuro.

4. Conseguir que el niño coopere con ellos.

En la Universidad de Granada, en el grupo de investigación que dirigía, desarrollamos una experiencia que implicaba estas habilidades, aunque tomadas como prevención del fracaso escolar ${ }^{36}$. No obstante, un procedimiento global consiste en promover valores humanos. La vía analítica para cada uno de ellos la proporciona Isaacs ${ }^{37}$.

En cuanto a los programas, pretenden que los perpetradores controlen su ira y estrés. Las estrategias que incluye son:

1. Detectar los rasgos fisiológicos y cognitivos asociados con la alta excitabilidad.

2. Sustituir los pensamientos que producen ira por otras ideas más positivas.

3. Desarrollar técnicas de autocontrol.

${ }^{35}$ Cfr. En el libro escrito por F. Corominas (1991) Cómo educar a tus hijos. Madrid, Palabra, se insertan unas propuestas para la actuación de los padres en el sentido de tales apartados.

${ }^{36}$ Morales, A.: Prevención del fracaso escolar a través de la tutoría con la familia, en Peiró, S. (1995) Familia, educación de adultos y hogares en situación de riesgo. Granada, Adhara Ediciones, col. Biblioteca de Estudios Universitarios; pp.89 y ss.

${ }^{37}$ Isaacs, D. (1979) La educación de las virtudes humanas. Pamplona, Eunsa. En concreto y sobre la relación positiva; véase la voz "flexibilidad". 
B) Con relación al desarrollo de interacciones positivas (disfrutar con los hijos), que lleven a la alegría en familia, diversiones, etcétera, confróntese la experiencia aludida sobre (re)educación de adultos ${ }^{38}$. Se trata de usar el modelo conformado por estrategias cognitivas que consiste en hacer que los padres perpetradores comprendan en qué medida sus ideas acerca de las personas y situaciones influyen en su comportamiento. Por lo general este problema suelen tenerlo padres con una baja autoestima. En este caso, el trabajo del terapeuta consiste en lograr que el padre supere estas ideas erróneas para sustituirlas por otras más positivas.

Para tratar a los padres que maltratan físicamente o abandonan a sus hijos, los métodos más aceptados actualmente son los cognitivo-conductuales ya que sirven para modificar las características más significativas de los padres perpetradores. En estos programas se enseñan técnicas como la relajación, autocontrol o reestructuración cognitiva, del mismo modo se prepara a los padres para resolver problemas y para controlar el estrés y la ira, combinando todo esto con el aprendizaje de las habilidades básicas para educar a los hijos.

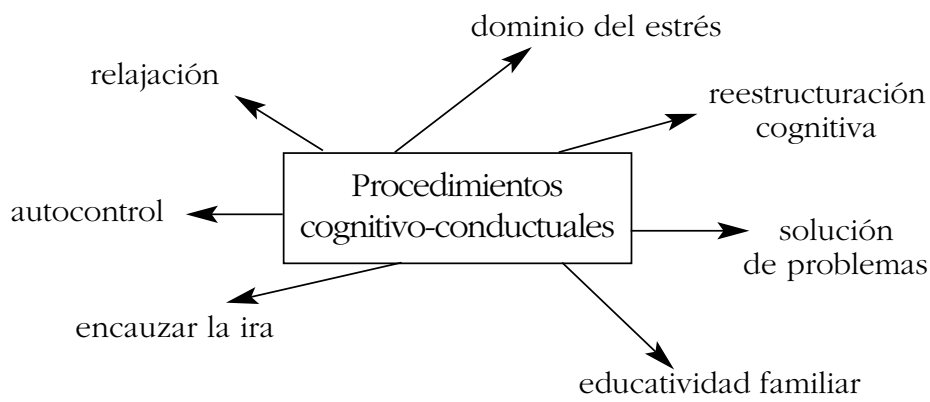

\footnotetext{
${ }^{38}$ En Peiró (1993: op. cit., pp.345-348) se insertan 12 fichas de trabajo para que, cumplimentándolas sobre realidades vivenciales, se logre la cohesión de los miembros de las familias nucleares y amigas en situación de riesgo, bajo la perspectiva de compartir valores humanos. En otra publicación (1995: Familia, educación de adultos y hogares en situación de riesgo, Granada, Adhara, pp.143-183) se ofrece una aplicación valorada empíricamente.
} 
No obstante, no se trata de plasmar en abstracto estas competencias, se lograría un aprendizaje alejado e inaplicable a la realidad, a la vez que anodino. Para salvar la situación es aconsejable mantener un sentido cuyas notas ${ }^{39}$ sean:

1. Enseñar a reflexionar antes de cada acto o decisión.

2. Usar los propios recursos para ver las cosas de otra manera.

3. Conocerse, para reajustarse, valorarse y efectuar una autoestima objetiva.

4. Lograr la eficacia en las acciones a emprender, evaluarlas.

5. Desarrollar la sinergia en las relaciones humanas.

6. Detectar las barreras que impidan una comunicación familiar y eliminarlas.

7. Introducirse y contagiar en fuentes de la cultura que no sean triviales, groseras, alienantes.

8. Enseñarse a exigir(se $)^{40}$ para educar.

C) Tratamientos centrados en las víctimas. Nuestros estudiantes suelen ser el centro sobre quienes gira la denuncia, violencias, efectos primarios (sobre las víctimas) y secundarios (contaminados por los efectos de los malos tratos). Además, abundando en la cuestión, hay que tener en cuenta que el trato vejatorio puede dejar huellas importantes en la constitución de la personalidad en proceso de configuración.

Si tenemos presentes los parámetros constituyentes de la subjetividad humana (estructura del yo), habrá que saber y comprender cómo está afectado en el autoconcepto y valoración de sí mismo. Esto nos lleva a saber cómo está en la estima y ajuste axiológicos, así como si hay distorsión en su jerarquía de valores, si los tiene claros, qué modelado existe, y si hay o no etiquetado, etcétera.

Por tanto, hay que intervenir en el refuerzo de aquellas áreas o cualidades que sean importantes desde el punto de vista del desarrollo del la personalidad. Además de actuar

${ }^{39}$ Con el fin de profundizar en cada uno de estos aspectos, entre otros, aconsejo la consulta del libro de Aguiló, A. (1996) Carácter y valía personal. Madrid, Palabra.

${ }^{40}$ Ferrer, E. (1989) Exigir para educar. Madrid, Palabra. 
sobre los problemas específicos consecuentes del maltrato. El tratamiento debe ir dirigido a lograr un equilibrio entre los desajustes de la víctima y la educatividad de los padres.

\section{CONCLUSIONES Y PROPUESTAS PARA LA SISTEMATIZACIÓN DE PROGRAMAS}

1. Ni las enseñanzas dentro de las aulas pueden concebirse ajenas al entorno, ni el centro está aislado del mundo como si se le impusiera una campana de cristal, ni el trasfondo psíquico del sujeto se deja detrás de la puerta antes de entrar al centro. Por consiguiente, los procesos educativos (instructivos, con los formativos, más de logro del autocontrol) han de implicar tanto las funciones docentes como de tutoría y psicopedagógicas, pero no trabajando multi/pluridisciplinariamente, sino en colaboración interdisciplinar, con la mirada puesta en la consecución de valores humanos (sociales e individuales). En consecuencia, urge procurar el trabajo en equipo y generar la verdadera comunidad educativa, que trascienda la mera colaboración escolar.

2. Si hoy la cuestión toma gran realce, ha sido la Psico-sociopedagogía la que ha tomado cartas en el asunto en tiempos recientes. Por esto y lo actual, afirmamos que paralelamente a estos datos, la violencia escolar crece en las casas, se extiende por los barrios, y se contagia y cultiva en los patios, promoviendo situaciones insostenibles en el interior de las aulas. La interpretación pedagógica de este ambiente externo se concreta en la expresión de una profesora del IES de Elche: «los alumnos tienen muchos derechos, pero pocos deberes". Corolariamente, habrá que promover, primordialmente, el ejercicio y asunción de la normatividad en cada estudiante. No se trata de un aplicar administrativo del reglamento, sino de generar la conexión entre conciencia, culpa, norma y valores.

3. El hecho tan generalizado de expulsar a los estudiantes conflictivos de los centros se puede traducir en una desresponsabilización del sistema. Esto puede interpretarse como 
una medida discriminatoria, si no xenófoba, aunque para mí trasluce la carencia de ciertas competencias pedagógicas propiciatorias para cohesionar a los estudiantes, de promover motivos, etcétera, en fin, de efectuar una tutoría personalizante.

4. Un aspecto similar es la tendencia a aplicar el reglamento de régimen interno. Por ejemplo, en lo mencionado sobre derivar los casos a Juzgados y Fiscalía. Ya señalaba en un trabajo anterior que ésta es una medida que enfría las relaciones cohesionantes de la acción educante.

5. El profesorado va cayendo en una situación insuperable, quedando señalado por un malestar psíquico que le lleva a estar al borde de la depresión. Sobre esto se cuentan bastantes causas de bajas relacionadas con la agresión. Pero también, el profesional de la educación se está cansando de no recibir apoyos por parte de la estructura del sistema educativo. Ello genera la pasividad, que es aprovechada por los escolares al percibir cierta incertidumbre docente. Por lo que esto exige un lote combinado de medidas legales, administrativas, dignificación al profesor y creación de un foro de discusión para optimizar la posición de los enseñantes.

6. Llama poderosamente la atención, la superabundancia de negligencias con relación a los malos tratos. Tal casuística puede ser explicación de diferentes tipos de anomias, con sus correspondientes derivaciones en cuanto a indisciplinas, conflictos..., violencias o malos tratos, en suma.

7. La incidencia de las violencias ha sido prácticamente nula en el último quinquenio y en las comarcas valencianas caracterizadas por disfrutar de una mayor cohesión entre los conciudadanos de las localidades, siendo la comunión en ciertos valores humanos lo que mantiene el clima de comunidad. Corolariamente, habría que fomentar los valores humanos, costumbres, estilo propio de cada centro, con el fin de recuperar la participación y buena voluntad de las poblaciones. Lanzo la idea de comunidad y educación. 
8. Sin caer en condicionamientos, habrá que plantear situaciones de prevención y de corrección, como pueden ser las acomodaciones de los currícula de educación de adultos, así como los de ESO y Bachiller, en ciertos aspectos relacionados con educación sexual, transversales, etcétera.

9. Y todos los extremos anteriores no acabarán con éxito si el profesor no pasa de una situación reactiva, de búsqueda del mero respaldo administrativo, de aparatos legales, etcétera, a una autoimplicación por mejorarse. Esto lleva a que cada día reconsidere la calidad de su asignatura, el valor de cada tema, los procedimientos y técnicas más apropiados para cada noción, lo cualitativo de la evaluación...

10. El centrar a la familia como protagonista nos lleva a intentar desarrollar una educación de adultos que atienda la misión de la maternidad/paternidad, sobre el modo de ejercerla y de mantener una relación educativa. Sobre todo habría que enseñar habilidades y competencias, junto a los valores y actitudes, que contrarresten la negligencia. Por consiguiente, pensemos en formar a cada miembro en conjuntos de valores que tiendan a promover un ambiente positivo para la relación comunicativa, habilidades sociales dialógicas, valores promotores de la socialidad, etcétera.

11. Si bien las medidas directas sobre la violencia no se refieren exclusivamente a "educación", las preventivas se compaginan entre "asuntos sociales" e "interior" principalmente, pero no es descartable implicar la sanidad y cultura con educación.

Estas proposiciones pueden resumirse así: para solucionar los problemas de la violencia educacional, habría que dejar de mirar hacia lo meramente estructural, para pasar a una fase caracterizada por la actitud de actuar en convergencia todos a la vez, que no significa una mera enseñanza comprensiva. 